\title{
Revision of Ordnance Plans from Air Photographs
}

\author{
By Colonel H. L. Crosthwait, C.I.E.
}

$\mathrm{I}^{\mathrm{N}}$ the Interim Report of the Departmental Committee on the Ordnance Survey, discussed in NATURE of May 2, p. 719, reference is made to the employment of air photographs as a means of speeding up the revision of the 25-in. Ordnance plans. It is proposed in this article to indicate in general terms how this can be done.

The area it is proposed to revise is divided up into rectangular blocks of about 10 miles side. The aircraft, carrying a camera* which automatically exposes a roll of photographic film at prearranged intervals, is flown to follow a straight course over the ground, and parallel strips are photographed so as to cover the area as shown in the diagrammatic illustration (Fig. 1). For this particular purpose a lens of 20 -in. focal length is employed, from a height of about 8,000 feet, giving a scale of approximately $1 / 5,000$. These photographs are afterwards enlarged without rectification to a scale of 25 -in. to the mile or $1 / 2,500$. During the flight, the exposure of successive photographs of a strip is so timed that they overlap each other in a forward direction by about 60 per cent, and the strips are arranged to have a lateral overlap of about 25 per cent. If the work is skilfully carried out, the whole area should be covered by strips of photographs without leaving any gaps. The chief object, among others, of giving the photographs an overlap of 60 per cent, is that adjacent photographs of the same strip may be viewed in a stereoscope, which gives an impression of the ground in relief, greatly facilitating the interpretation of objects which might otherwise be doubtful.

It will be noticed that each object is photographed at least twice. Only in the case of level ground where the exposure has been made with the axis of the camera pointing vertically downwards, and where the lens used covers the film

"The camera used is known as the "Eagle", made by The Williamson Manufacturing Co. without distortion, will the resulting photograph give an accurate map representation of the ground as seen from the air. In practice, the two conditions of a vertical axis and level ground are scarcely ever realised, while lenses are now made practically

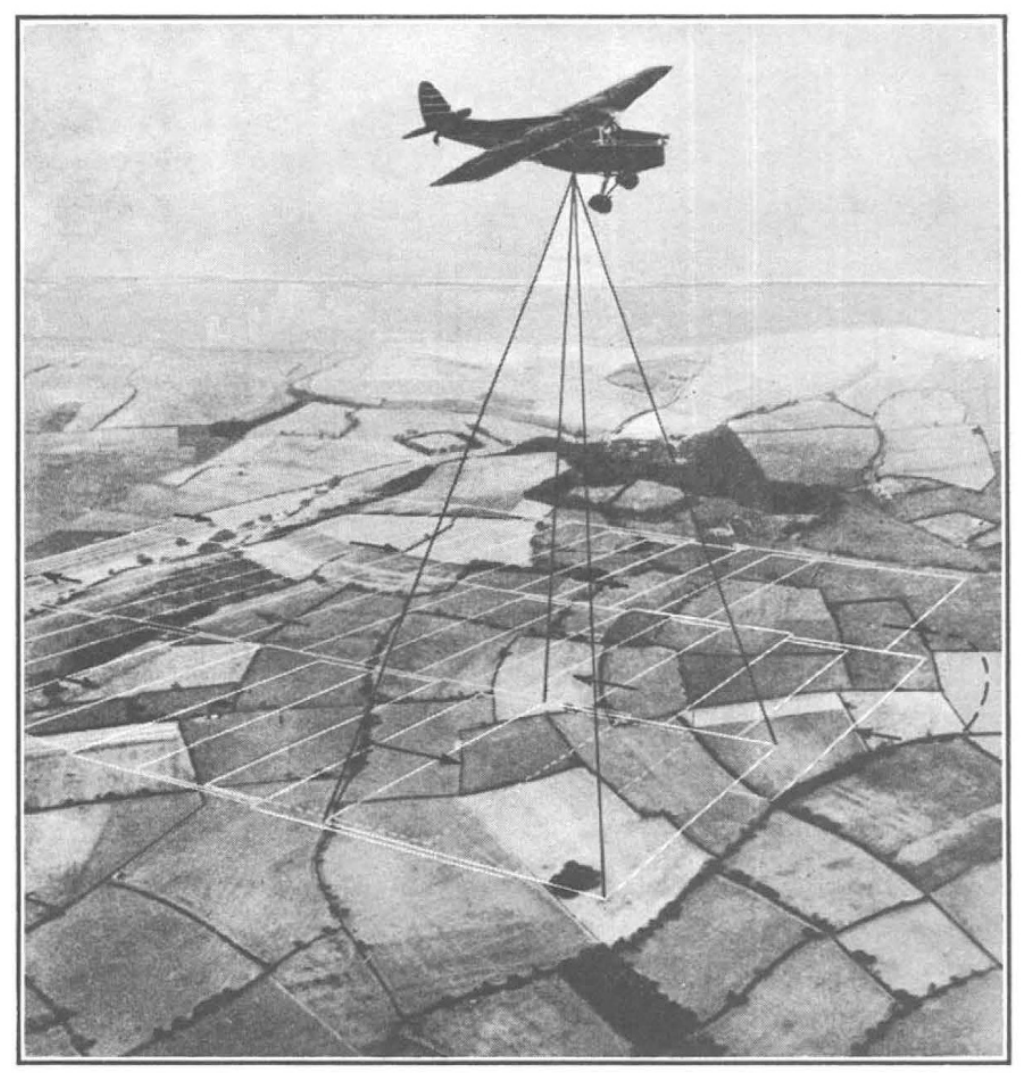

FIG. 1. Diagram illustrating how an aircraft covers the area to be photographed. By permission of Aerofilms, Ltd.

free from distortion within the limits they are required to cover. It becomes necessary, therefore, to subject the photographs to some form of rectification in order to counteract the effect of camera tilt, which should be kept as small as possible, and the deviation from the level of the ground. This can be done in several ways, but since we are only dealing with the application of air photographs to the revision of the 25-in. plans, we need only mention the method used for this particular purpose. There are few instances where there is not sufficient control on the old plan, in the form of unaltered detail, which can be recognised both on the plan and on the photograph. It is this control which is made use of in the epidiascope. Space will 
not admit of a full detailed description of the method or instrument, but we can indicate, in general terms, how the revision is carried out with the epidiascope.

The enlargement, derived from the negative taken from the air, which is, as stated, approximately on a scale of 25-in., is carefully examined with the old plan, and new detail is inked up in red. In doing this the draughtsman is aided by the stereoscope, in which has been placed the pair of overlapping photographs relevant to the area under revision. He then selects suitably placed ments have been simplified. It consists of a horizontally placed photo-board over which has been inverted an ordinary camera the back of which forms the plan-board. The photo-board is capable of being tilted about a horizontal and vertical axis. To it the photograph can be secured in any desired position under a sheet of plate-glass on which the two axes are marked. The photograph is set so that the base of the triangle to be revised coincides with the horizontal axis, with its mid-point at the intersection of the two axes. An image of the highly illuminated photograph is

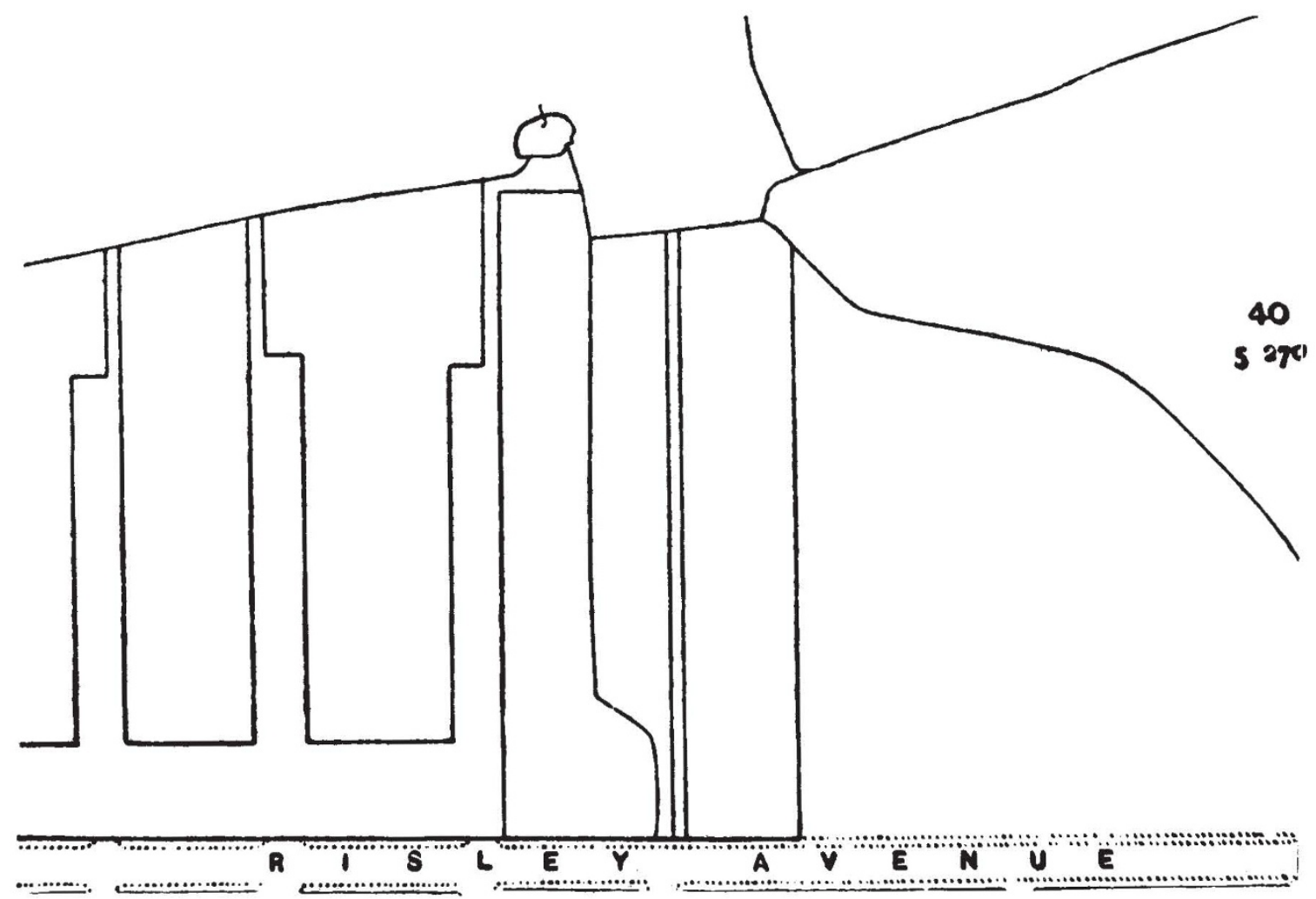

FIG. 2. Air survey of Tottenham. Reproduction of a section of a 25 in. Ordnance plan representing the area covered by the air photograph

(Fig. 3). This plan was revised in 1913. Reproduced from the Ordnance Survey Map, with the sanction of the Controller of H.M.

and well-defined points of detail appearing both on the photograph and the old plan, to form triangles covering the area, later to be fitted to the plan in the epidiascope.

The ideal triangle for rectification would be one which embraced an area on a uniform slope proceeding from the base of the triangle. With this object, points selected should be sited, if possible, on high ground and at the bottom of valleys. For this purpose the 6 -in. contoured map can be consulted, assisted by the relief view of the area in the stereoscope. The Ordnance Survey employs a modified form of epidiascope* in which the move-

* For a full description of the epidiascope made by Messrs. Barr and Stroud, see "Surveying from Air Photographs", by Capt. M. Hotine, R.E. formed on the matted surface of a sheet of drawing celluloid, on which has been printed, in grey, an impression of the old plan, placed on the glass camera back or plan-board. The image of the base of the triangle being revised is made to coincide with the corresponding base on the print of the old plan, any small difference of scale being adjusted by a slight movement of the camera lens. The photo-board is then tilted so as to make the triangles fit one to the other. The new detail, which has already been inked up on the photograph, is then drawn in on the celluloid print of the old plan. The same process is repeated, triangle by triangle, until the whole area has been revised. This drawing forms the 'field trace', but 


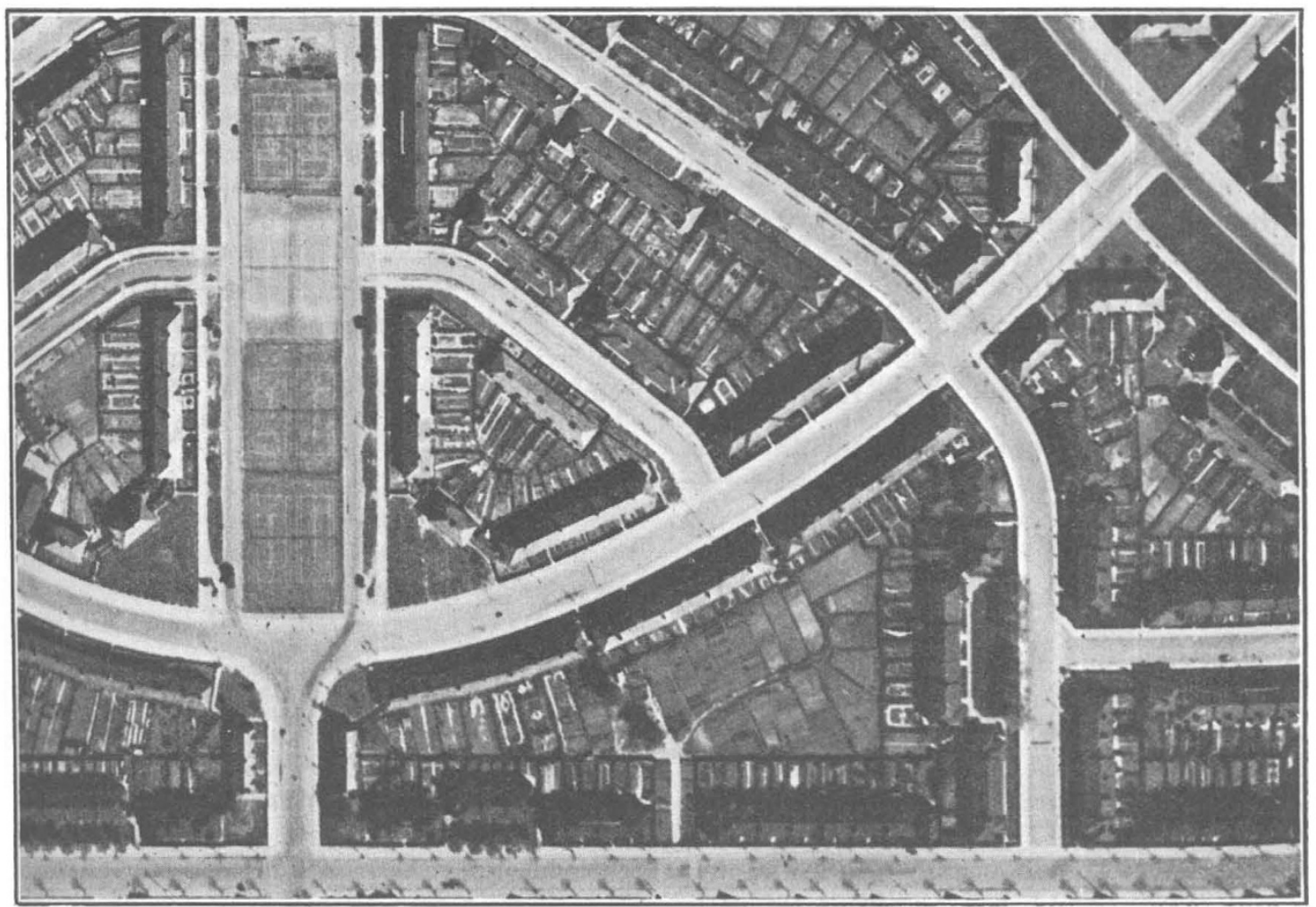

FIG. 3. Air survey of Tottenham. Vertical air photograph taken in June 1935 of same area as Fig. 2 , scale 25 in. to a mile. By permission of Aerofilms, Ltd.

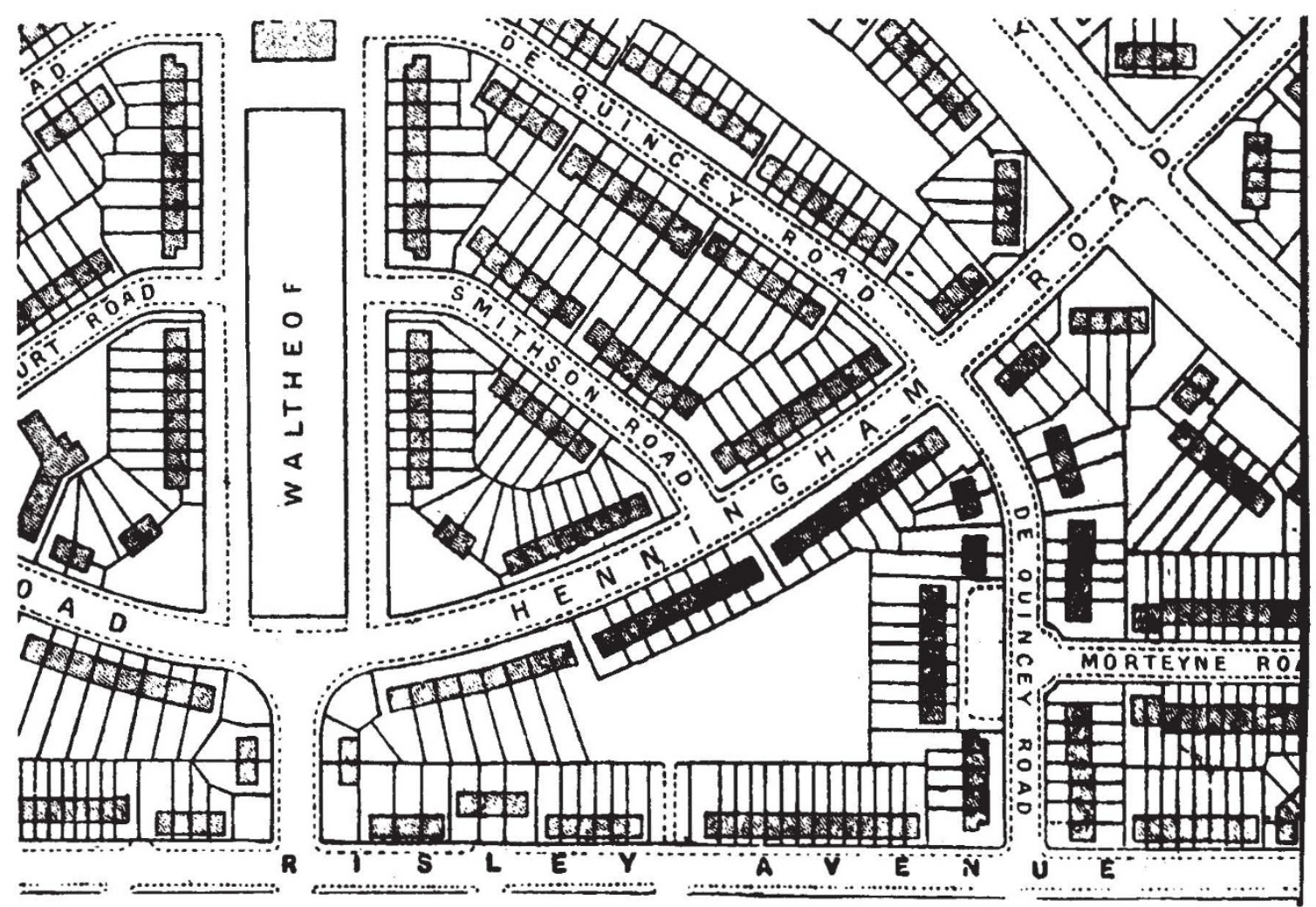

Fig. 4. Air survey of Tottenham. Resulting plan; scale 25 in. to the mile, plotted from photograph (Fig. 3). By permission of Aeroflims, 
since it is deficient in new names, boundaries and details such as wire fences, which fail to show up on the photograph, or which have been obscured by shadows, it is taken into the field for final revision. From it, when finally revised, the fair plan is drawn in the ordinary way. This, shortly described, without going into detail, is the process employed in revision from air photographs using the simplified epidiascope.

Owing to the small tilt of the photographs, which should not exceed some $2^{\circ}$, and the small area embraced by the triangles, the residual errors due to the theoretical inexactitude of the epidiascope design are so small as to be negligible. The advantage of the modified machine is that it is cheap to construct, a consideration of importance where a good many of them are required to deal expeditiously with a large number of photographs; also it is simple to operate.

Fig. 2 is a reproduction of a portion of an old plan; Fig. 3 a photograph of the same area as it now exists and Fig. 4 the resulting plan plotted from the air photograph.

\section{Archæological Discoveries at Předmost}

$\mathrm{T}$ HE site in Moravia known to archæologists as Předmost actually is, or was, a small hill to the west of the little village of Predmosti, which lies about two kilometres north of Prerov, a junction on the Central European line between Warsaw and Vienna. The hill rose to a height of forty metres above the marshy plain, and was known locally as "Hradisko" (oppidum), evidently having served the inhabitants as a place of refuge in time of war. The substructure of the hill consisted of two limestone rocks joined by a saddle of yellow brick-earth, or loess. The complete quarrying away of one of these rocks many years ago has exposed the face of the loess, and at the base level of the rock in a band of darker deposit have been found relics of prehistoric man in such a quantity and of such a character as to justify the verdict that this is one of the most important palæolithic sites ever discovered.

The former inhabitants had evidently used the rock as an abri, or shelter, and had lived by hunting, mainly of the mammoth. Relics of this animal are almost innumerable. A thousand teeth and five milk-teeth have been found, and of the tusks, complete or broken, there are some hundreds. In the first series of explorations of the site, no less than twenty thousand implements of stone, bone and ivory were collected, while the carvings and engravings of ivory and bone are æsthetically and culturally of great interest and importance. The outstanding feature in the discoveries which have been made, however, is an assemblage of the skeletal remains of early man, in which twenty individuals were represented in a single find. The ethnic character of these individuals is no less interesting than the conditions in which they were found.

The first recorded discovery at Předmost was made so long ago as 1571 , when "giants' bones" were discovered by John Blahoslav; but it was first recognised as a palæolithic station by Dr. J. Wankel in 1880 and 1881 as the result of an investigation which had begun in 1878. The great explorer of Předmost, however, was K. J. Maska, a schoolmaster, who first turned his attention to the site in 1882, and excavated it systematically and continuously in the ten years 1884-94. It was in this last year that he made his sensational discovery of human remains, when, as already mentioned, skeletons and parts of skeletons representing twenty individuals were found in a small space, an elliptical grave, measuring 4 metres long by 2.5 metres wide by $30 \mathrm{~cm}$. deep. These remains were closely packed, side by side and one upon another, in a crouched position, the heads in most instances towards the north. They lay in the loess above undisturbed quaternary deposits, but separated from them by a calcareous layer $30-50 \mathrm{~cm}$. in thickness. Above the skeletons was the complete skull of an Arctic fox, at the north-west edge was a fragment of the shoulder-blade of a mammoth, which had been graven by a flint tool, and at the south-west lay a complete mammoth shoulder-blade. Two lower jaws of the mammoth, found two metres away, may be related to the burial. Other finds adjacent were fragments of flint and jasper and carbonized bones. Stones to a thickness of $40 \mathrm{~cm}$. had been piled above the interment. Nevertheless, gnawed human bones nearby, and the incomplete condition of some of the remains, suggest that these stones had not availed to keep away beasts of prey.

Unfortunately, no photographic record or drawing was made of the find; and discrepancies in detail have gained currency in accounts of the discovery. The finds associated with the skeletal remains and their position mentioned above are those recorded by Dr. J. Matiegka, to whom Maskra's material was entrusted. 